\title{
MAPPING FAULT SLIP IN CENTRAL CALIFORNIA USING SATELLITE, AIRBORNE INSAR AND GPS
}

\author{
Zhen Liu $^{(1)}$, Paul Lundgren ${ }^{(1)}$, Scott Hensley ${ }^{(1)}$ \\ (1) Jet Propulsion Laboratory, California Institute of Technology, 4800 Oak Grove Drive, Pasadena, CA 91109 USA
}

Email:Zhen.Liu@jpl.nasa.gov

\begin{abstract}
The central San Andreas fault is accommodating relative motion between the Sierra Nevada-Great Valley block and the Pacific plate in central California. It is creeping along the $\sim 60 \mathrm{~km}$ long central segment while changing to locking towards the northwest and southeast. Characterizing its creeping nature and on and off-fault deformation are crucial for improved earthquake hazard assessment in the region. We use Lband ALOS PALSAR, NASA airborne UAVSAR data and geodetic measurements to map the fault slip variation. Our results show a distinct change in shallow fault creep and fault slip at depth from the central creeping to the transitional segment. Our work demonstrates that airborne UAVSAR provides useful constraints on shallow creep and near fault deformation. Continuing observations would be essential in capturing time-varying faulting behaviours and their implication towards present and future earthquake activities.
\end{abstract}

\section{Introduction}

The improved spatiotemporal resolution of surface deformation from recent satellite and airborne InSAR measurements provides great potential to improve our understanding of faulting processes and earthquake hazard for a given fault system. A major plate boundary fault in central California, the central San Andreas fault (CSAF) displays a spectrum of complex fault slip behaviours with creeping in its central segment that decreases towards its northwest and southeast ends where the fault transitions to being locked (Fig. 1). In the north the CSAF branches into two sub-parallel faults (northern San Andreas fault and Calaveras-Paicines fault) that are both actively accommodating plate motion. To the south, near the Parkfield transition, large earthquakes have occurred with at least six $\mathrm{Mw} \sim 6.0$ events since 1857, most recently in 2004. Large earthquakes have also occurred in the off-fault region such as the December 22, $2003 \mathrm{Mw}$ 6.5 San Simeon earthquake and the May 2, $1983 \mathrm{Mw} 6.5$ Coalinga earthquake, suggesting significant off-fault deformation. Despite considerable progress in characterizing faulting process using in-situ geodetic and InSAR observations, a thorough understanding of this complex fault system remains elusive.

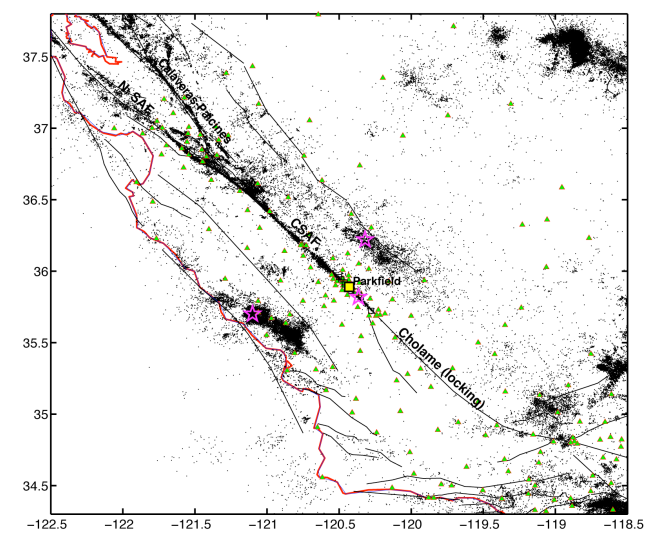

Figure 1. Tectonic settings and major faults in central California. Stars represent epicentres of 2004 Parkfield, 1983 Coalinga and 2003 San Simeon earthquake. Green triangles are campaign and continuous GPS sites in the region. The black dots are regional seismicity

(http://www.ncedc.org/anss/catalog-search.html).

The important questions regarding this system are: How is the relative plate motion accommodated between the CSAF and off-fault secondary faulting structures? What are the spatiotemporal variations of fault slip rates and locking? What is the depth extent of shallow slip deficits and their implication for future earthquake hazard?

\section{Data Analysis}

To understand the complexity and variety of fault slip behaviors and fault mechanics, we integrate satellite and airborne synthetic aperture radar (SAR) repeat pass interferometry (RPI) observations, with GPS measurements from the Plate Boundary Observatory (PBO) (http://pboweb.unavco.org) and campaign and regional networks to estimate fault slip and shallow slip deficits along the CSAF [1]. Existing C-band ERS-1/2, Envisat and Radarsat SAR data provide long archives of SAR data over the region but are subject to severe decorrelation. The Japan Aerospace Exploration Agency's ALOS-1 satellite has made less frequent acquisitions (5-6/yr per track) since 2006 but its PALSAR L-band sensor provides much improved coherence compared to shorter wavelength radar data but less optimal viewing geometry for imaging fault slip. 

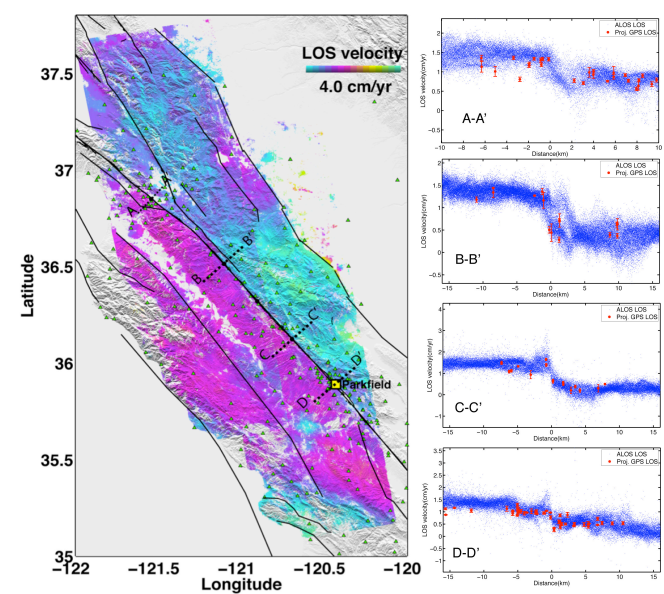

Figure 2. ALOS-1 line-of-sight velocity map over 20072011. Comparison of selected profiles along the strike with projected GPS LOS velocities is shown in right panel (red-GPS, blue-InSAR). Clear variation is seen along the strike.

More recently, the NASA UAVSAR airborne SAR has repeated fault perpendicular adjacent swaths imaged from opposing look directions and fault parallel swath flights over the CSAF, providing improved imaging of fault slip related deformation at finer spatial resolution than previous platforms $(\sim 6 \mathrm{~m}$ at 12 azimuth $\mathrm{x} 3$ range looks) [2]. We processed ALOS radar data between 2006 and 2011 using JPL/Caltech ROI-PAC software, and estimated and removed long wavelength linear ramp using in-situ GPS as control points. We perform the stacking to suppress atmosphere noise by selecting interferogram pairs with minimal ionosphere noise and short spatial yet longer temporal baselines. The resultant ALOS LOS velocity shows clear variation in deformation at different transacts, suggesting nonuniform slip variation along the strike (Fig. 2). For the UAVSAR data, we use the selected RPI pairs from the fault perpendicular swaths that have time intervals $>2$ years and lower noise level. Released unwrapped RPI pairs tend to have too much masking near the fault due to the ICU phase unwrapping issue. We perform powerspectrum and low-pass filtering, reunwrapping the phase, and geocoding for all UAVSAR pairs used in the analysis. The SNAPHU minimum cost flow algorithm is used in the phase reunwrapping. We mask the unwrapped interferograms based on the correlation estimated from filtered phase gradient. Typical unwrapped RPI shows much clearer phase discontinuity due to fault creep (Fig. 3).

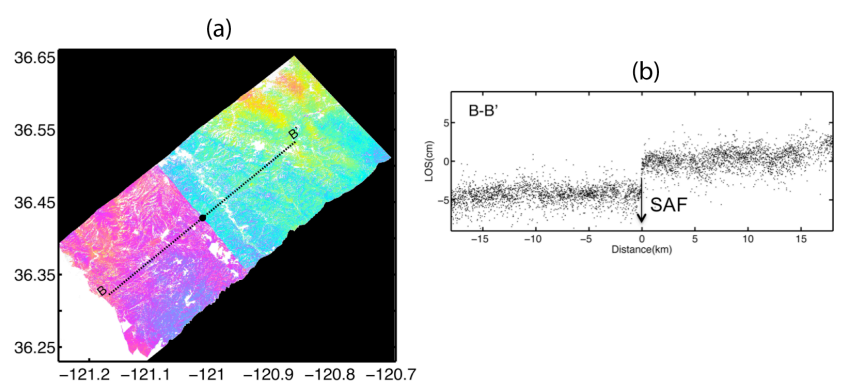

Figure 3. (a) Unwrapped UAVSAR interferometry between February 20, 2009 and November 18, 2010 in the central SAF region. (b) Profile across the fault showing the clear fault creep signals.

\section{Modelling method}

We use an anti-plane dislocation model that consists of a dextral strike-slip dislocation in an elastic half-space to invert for fault slip at depth [3]. We choose $12 \mathrm{~km}$ as nominal seismic-aseismic transition depth based on seismicity and previous studies [4]. The fault slip is parameterized from $0-12 \mathrm{~km}$ into layers with uniform slip in each layer. A deep dislocation extending from $12 \mathrm{~km}$ to infinity is assumed to creep at long term slip rate and used to simulate interseismic strain accumulation. We minimize both weighted data misfit residual and roughness with non-negativity constraint on fault slip via a weighted Least Square method. The UAVSAR and InSAR uncertainties are assigned based on correlation and data scattering, which are at $\sim \mathrm{cm}$ level while projected GPS line-of-sight velocity uncertainties are at a few $\mathrm{mm} / \mathrm{yr}$ level. Synthetic tests with assumed known fault slip distribution at depth show that the method can successfully retrieve the input slip distribution. Fig. 4 shows the slip inversion and model fit using one transect in the central creeping segment as an example.
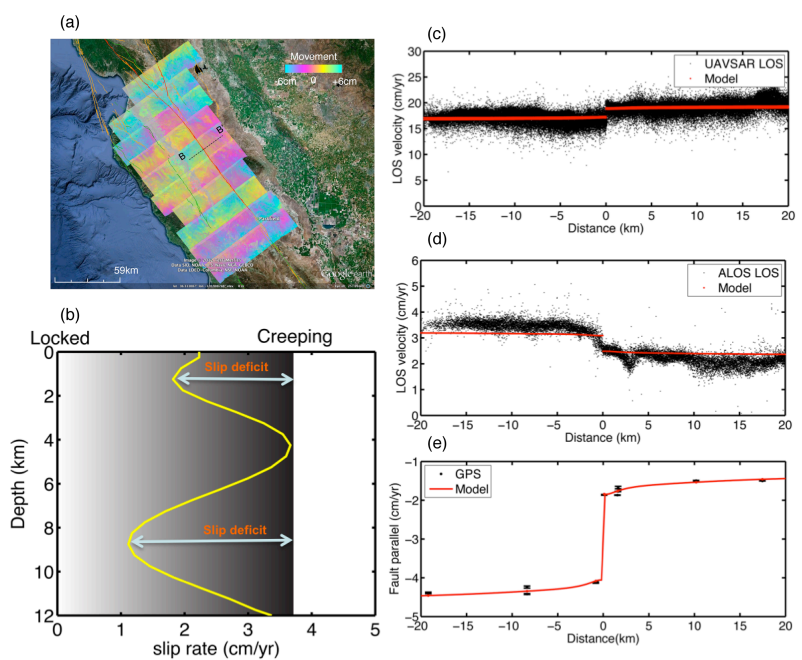

Figure 4. (a) The mosaic view of UAVSAR interferometry from fault perpendicular paths in the central California. (b) Inverted fault slip at the selected profile indicated in (a). The slip distribution and long 
term slip rate can be used to determine the slip deficit with depth. (c) UAVSAR LOS rate (black) vs. model fit (red). (d) ALOS LOS rate (black) vs. model fit (red). (f)

Projected GPS LOS rate (black) vs. model fit (red).

\section{Results}

We modelled fault slip at a series of fault transects from the northeast creeping section to south of the Parkfield segment (Fig. 5).
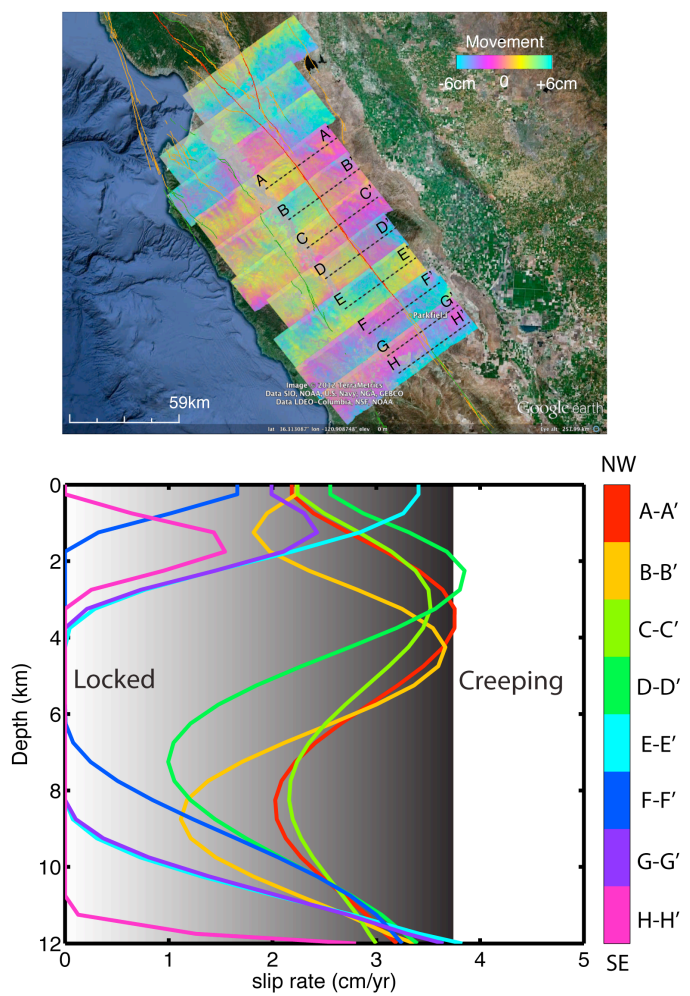

Figure 5. (Top) Selected slip profiles from north to south along the CSAF. (Bottom) Fault slip distribution color-coded based on the location along the strike.

Our results show that the central creep segment is characterized by non-uniform creep at shallower depth $(\sim 0-6 \mathrm{~km})$ and partially locked at upper crustal levels ( $\sim 6-10 \mathrm{~km})$ (Fig. 5). There is a distinct change in terms of shallow creep and slip deficit at lower upper crustal level from the central creeping segment towards the Parkfield transition where the fault creeps at shallower depths $(0-4 \mathrm{~km})$ and is locked at variable depth ranges. The inferred deep slip rates are $\sim 30-38 \mathrm{~mm} / \mathrm{yr}$ with most swaths of $\sim 33-36 \mathrm{~mm} / \mathrm{yr}$, comparable to previous studies [4]. We find that the fault slip rates at depths greater than $12 \mathrm{~km}$ are weakly constrained and subject to long wavelength noise components in the data.

\section{Conclusion}

Our results show that airborne UAVSAR data provide useful constraints on shallow fault slip thanks to the high spatial resolution and optimal looking geometry.
The joint inversion of L-band ALOS-1, UAVSAR and GPS data shows clear variation of surface creep and fault slip along the strike and at depth. Continuing monitoring and imaging of this part of plate boundary is crucial in capturing time-dependent transient deformation as suggested by seismicity analysis [5] and understanding their implication towards seismic hazard on and off the fault, and how the central SAF interacts with locking segments to the north and south.

\section{Acknowledgements}

ALOS PALSAR data is copyright JAXA/METI and was provided by the US Government Research Consortium Datapool at the Alaska Satellite Facility. We thank Jessica Murray at USGS for useful discussion. The research described in this paper was carried out at the Jet Propulsion Laboratory, California Institute of Technology, under a contract with the National Aeronautics and Space Administration.

\section{References}

[1] Rolandone, F., R. Bürgmann, D. C. Agnew, I. A. Johanson, D. C. Templeton, M. A. d'Alessio, S. J. Titus, C. DeMets, and B. Tikoff,, Aseismic slip and faultnormal strain along the central creeping section of the San Andreas fault, Geophys. Res. Lett., 35, L14305, doi:10.1029/2008GL034437, 2008.

[2] Hensley, S., K. Wheeler, G. Sadowy, et al., The UAVSAR instrument: Description and test plans, proceedings NASA Scienc Technology Conference 2007, 10p, 2007.

[3] Wei, M., D. Sandwell, Y. Fialko, A silent Mw 4.7 slip event of October 2006 on the Superstition Hills fault, southern California, J. Geophys. Res., 114, B07402, doi:10.1029/2008JB006235, 2009.

[4] Ryder, I., and R. Bürgmann, Spatial variations in slip deficit on the central San Andreas Fault from InSAR, Geophys. J. Int., 175, 837-852, doi:10.1111/j.1365246X.2008.03938.x, 2008.

[5] Tormann, T., S. Wiemer, S. Metzger, A. Michael, J. L. Hardebeck, 2013, Size distribution of Parkfield's microearthquakes reflects changes in surface creep rate, Geophys. J. Int., 193, 1474-1478, doi:10.1093/gji/ggt093. 